\title{
1789 Yılında Askerî Personel İçin Yazılmış Almanca-Türkçe Transkripsiyon Metni
}

\section{Beytullah BEKAR 1}

APA: Bekar, B. (2018). 1789 Yılında Askerî Personel İçin Yazılmış Almanca-Türkçe Transkripsiyon Metni. RumeliDE Dil ve Edebiyat Araştırmaları Dergisi, (12), 19-34. DOI:

$10.29000 /$ rumelide. 472750

\section{$\ddot{O} \mathbf{z}$}

\begin{abstract}
Türkçenin transkripsiyon metinleri, yabancılar tarafindan Türkçeyi öğretmek amacıyla hazırlanmış olan metinlerdir. Bazı transkripsiyon metinleri yalnız sözlük şeklinde hazırlanmış, bazıları sözlük ve gramer ilaveli hazırlanmıştır. Bazı transkripsiyon metinlerinde tematik olarak hazırlanmış konuşma cümleleri bulunurken bazılarında deyimler, atasözleri ve Nasreddin Hoca fikralarına yer verilmiștir Bununla birlikte bazı transkripsiyon metinleri Türkçe öğrenmek isteyen herkese yöneliktir, bazıları ise özel amaçla hazırlanmıştır. Thomas Chabert'in "Kurze Anleitung zur Erlernung der türkischen Sprache, für Militär Personen. Sammt einer Sammlung von nützlichen Gesprächen, Ausdrücken und Redensarten und einem Handlexikon der gebräuchlichsten Wörter" adlı transkripsiyon metni de başlığında belirtildiği üzere askeri personel için hazırlanmış bir eserdir.
\end{abstract}

Anahtar kelimeler: Almanca, Türkçe, transkripsiyon metni, Thomas Chabert.

\section{German-Turkish Transcription Text For Military Person Which Was Written in 1789}

\begin{abstract}
Transcription texts of Turkic are texts prepared by foreigners to teach Turkish. Some transcription texts are prepared only in dictionary form, some are prepared with dictionary and grammar adjuncts. Some transcription texts contain thematically prepared speech cues, while others include idioms, proverbs, and Nasreddin Hodja anecdotes. However, some transcription texts have been prepared for everyone who wants to learn Turkish, while others have been prepared for special purposes. Thomas Chabert's "Kurze Anleitung zur Erlernung der türkischen Sprache, für Militär Personen. Sammt einer Sammlung von nützlichen Gesprächen, Ausdrücken und Redensarten und einem Handlexikon der gebräuchlichsten Wörter” is a work made for military personnel.
\end{abstract}

Key words: German, Turkish, transcription text, Thomas Chabert.

\section{o. Giriş}

Transkripsiyon ve transliterasyon kavramlarıyla ilgili çeşitli tanımlar ve görüşler bulunmaktadır. Çalışmamızda ilkin transkripsiyon ve transliterasyon kavramlarıyla ilgili tanımlara kısaca değinilerek Thomas Chabert ve eseri “Kurze Anleitung zur Erlernung der türkischen Sprache, für Militär Personen.

1 Dr. Öğr. Üyesi, Kurklareli Üniversitesi, Fen Edebiyat Fakültesi, Türk Dili ve Edebiyatı Bölümü, beytullahbekar@gmail.com, ORCID ID: 00oo-0oo2-8372-119o [Makale kayıt tarihi: 25.9.2018-kabul tarihi: 13.10.2018] 
Sammt einer Sammlung von nützlichen Gesprächen, Ausdrücken und Redensarten und einem Handlexikon der gebräuchlichsten Wörter" hakkında bilgi verilecektir.

Transkripsiyon (çeviriyazı), Dilbilim Sözlüğünde (İmer, Kocaman, Özsoy, 2011: 73) "1-Dil seslerini düzenli ve tutarlı bir biçimde yazıya geçirme yolu. İki türü vardır: Sesbilimsel çevriyazı yatık iki çizgi içinde ve yalnızca dilde işlevi olan seşbirimleri gösterirken sesbilgisel çevriyazı, sesleri bütün söyleyiş ve duyuş özelliklerini göz önünde bulundurarak köşeli ayraç içinde gösterir. /b/ sesbilimsel, [b] sesbilgisel çevriyazı ile göstermeye örnektir. 2- Farklı abece kullanılarak yazılmış bir metni tüm özelliklerini koruyarak bir başka abeceye aktarma yolu." olarak tanımlanmıştır. Dilbilim ve Dilbilgisi Terimleri Sözlüğünde (Vardar, 1980, 51) ise "Gösteren düzlemindeki ses birim ve/ya da olgularını oldukları gibi, eksiltmeden yada çoğaltmadan yazılı biçime dönüştüren yazım türü. // En yaygın çeviri yazı yöntemi Uluslararası Sesbilgisi Derneğininkidir. Sesçil çeviriyazıya karşıt olarak sesbilimsel çeviriyazıda yalnız anlam ayırıcı ses olguları belirtilir.” şeklinde tanımlanır. (Vardar, 1980, 51).

Transliterasyon (harf çevirisi) her ne kadar transkripsiyon ile zaman zaman karıştırılsa da farklı bir uygulamadır. Dilbilim Sözlüğünde (İmer, Kocaman, Özsoy, 2011, 147) “Bir yazı sisteminde yazılmış bir metni başka bir yazı sistemine aktarma işlemi.” olarak tanımlanmış olup Dilbilim ve Dilbilgisi Terimleri Sözlüğünde (Vardar, 1980, 94) ise "Bir yazı dizgesindeki harfleri bir başka yazı dizgesine, belirttikleri sesleri göz önünde tutmadan, yalnızca karşılıklarını göstererek aktarma.” şeklinde tanımlanır.

Yukarıdaki tanımlardan hareketle yabancılar tarafından Türkçe öğrenmek ve öğretmek amacıyla hazırlanmış bu eserler farklı abece kullanılarak yazılmış bir metni tüm özelliklerini koruyarak bir başka abeceye aktarma yoluyla hazırlandıkları için transkripsiyon metinleri olarak adlandırılmaktadır. György Hazai, Türkiye Türkçesinin Dünü ve Bugünü (2012, 30-34) adlı çalışmasında bu eserleri transkripsiyon anıtları olarak adlandırmaktadır. Fakat Almanca "denkmal" in Türkçedeki karşılığı "anıt" olsa da Türkçe Sözlük’te (2005, 99) anıt için “Önemli bir olayın veya büyük bir kişinin gelecek kuşaklarca tarih boyunca anılması için yapılan, göze çarpacak büyüklükte, sembol niteliğinde yapı, abide.” tanımı kullanılmaktadır. Bu sebeple bu eserler için transkripsiyon metinleri denmesi daha uygundur.

Transkripsiyon metinleri yazı ve konuşma arasındaki farklılıkları, dönemin söz varlığını ve dil öğretim materyallerinin hazırlanış yöntemlerini tespit etme imkânı veren, aynı zamanda içinde barındırdıkları deyimler, atasözleri, bilmeceler, fikralar ve türkülerle kültürel değerleri günümüze taşımaları bakımından son derece önemli eserlerdir. Bu sebeple araştırmacıların ilgisi her geçen gün daha çok transkripsiyon metinlerine yönelmektedir. Bunun neticesinde değişik ülkelerde -özellikle de İtalya, Almanya, Fransa - Türkçe öğretimi amacıyla hazırlanmış iki veya çok dilli transkripsiyon metinleri bulunmuştur, bulunmaya devam etmektedir.

Türkçenin transkripsiyon metinlerinden ilki 14. yüzylla ait Codex Cumanicus'tur. Argunşah ve Güner (2015) tarafından çalışılan Codex Cumanicus 14. yüzyılda Karadeniz’in kuzeyinde yaşamakta olan Kıpçaklarla ticaret yapmak ve Hristiyanlığı yaymak amacıyla İtalyan tüccarlar ve Alman misyonerler tarafından hazırlanmış ve sonradan birleştirilmiş iki ayrı defterden oluşmaktadır. Birinci defter Latince ikinci defter ise Almanca hazırlanmıştır. 16. yüzyılda Bartholomæo Georgieuiz'in 1567 tarihli "De Tvrcarvm Moribvs Epitome” adlı eseri; 17. yüzylda Meninski’nin Thesaurus Linguarum Orientalium, Turcicae, Arabicae, Persicae (Doğu Dillerinden Türkçe, Arapça ve Farsçanın Hazinesi), Jacobus Nagy de Harsany'nin 1672 tarihli "Colloquia Familiaria Turcico Latina Seu Status Turcicus Loquens" adlı eserleri; 18. yüzyllda Johann Matthias Korabinsky'nin 1788 tarihli "Versuch eines kleinen Türkischen Wörterbuchs mit beygesetzten deutsch, ungurisch und böhmischen Bedeutungen und einer 
kurzgefaßten türkischen Sprachlehre", Thomas Chabert'in 1789 tarihli "Kurze Anleitung zur Erlernung der türkischen Sprache, für Militär Personen. Sammt einer Sammlung von nützlichen Gesprächen, Ausdrücken und Redensarten und einem Handlexikon der gebräuchlichsten Wörter”, J. Preindl' in 1790 tarihli "Grammaire Turque: D'une toute nouvelle methode d'apprendre cette langue en peu de semaines avec un vocabulaire." transkripsiyon metinlerinden bazllarıdır.

Çalışmamızda Thomas Chabert'in 1789 tarihli “Kurze Anleitung zur Erlernung der türkischen Sprache, für Militär Personen. Sammt einer Sammlung von nützlichen Gesprächen, Ausdrücken und Redensarten und einem Handlexikon der gebräuchlichsten Wörter" adlı eseri tanıtılacak olup askeri personele özgü hususlar tespit edilmeye çalışlacak ve yazılmış olduğu dönemin dil hususiyetlerini yansitan özelliklere değinilecektir.

\section{Yazar Hakkında Bilgi}

Eserin hiçbir yerinde yazarın ismi geçmemektedir. Aynı şekilde bu kitap hakkında bilgi veren Jahrbücher der Literatur, 54. Band $(1831,67)$ adlı eserde, eserin yazarının adının belirtilmemiş olduğu bildirilmektedir. Fakat Die K.K. Orientalische Akademie zu Wien, ihre Gründung, Fordbildung und gegenwärtige Einrichtung $(1839,56)$ adlı eserde adı geçen transkripsiyon metninin Thomas Chabert'e ait olduğunu belirtilmektedir.

Thomas Chabert 1766 yılında İstanbul'da doğmuştur. Fransız kökenli bir aileye mensuptur. Babası Jean-Joseph Polonya ve Sicilya krallıklarında tercümanlık yapmıştır. Annesi Lucie Tomagian ise Katolik bir Ermenidir. 1779 yılında Viyana Akademi'sine kabul edilmiş, 1785 yılında Doğu Dilleri profesörlüğünü almış ve 1817 yılına kadar bu kürsüde çalışmıştır. Thomas Chabert’in 1810 yılında Türkçe yazmış olduğu Hikâyet-i İbda-i Yeniçeriyân bâ Bereket-i Pîr-i Bektaşiyân Şeyh Hacı Bektaş Velîi Müslimân adlı tiyatro eser Şair Evlenmesi’nden önce Türkçe olarak verilmiş oyunlardandır (GökalpAlpaslan 2007, 40-68).

\section{Eser Hakkında Bilgi}

Eser, 1789 yılında basılmış olup Floransa Merkez Milli Kütüphanesine bulunmaktadır. Esere kütüphanenin dijital arşivinden ücretsiz olarak ulaşılabilmektedir. Eser, bir giriş ve dört bölüm olmak üzere toplam 178 sayfa olarak hazırlanmıştır. Birinci bölümde isimler ve isimlerle ilgili bazı özellikler, ikinci bölümde zamirler ve zamirlerle ilgili bazı özellikler, üçüncü bölümde filler ve fillerle ilgili bazı özellikler ve dördüncü bölümde cümle kalıpları, tematik konuşma cümleleri ve sözlük kısmı verilmiştir. 


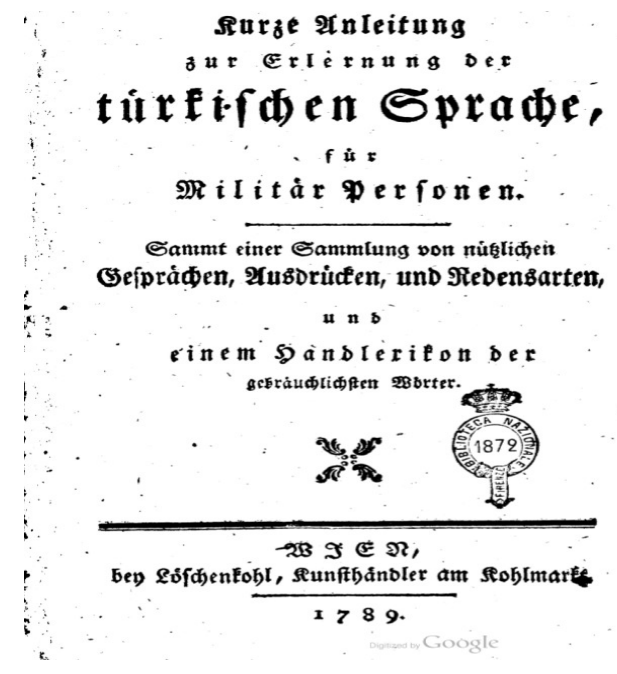

Resim 1. Eserin adı, basım yeri ve yılı bulunan ön sayfa

Transkripsiyon metinlerinin çoğunda yazarlar eserlerinde kullandıkları transkripsiyon sistemleri hakkında bilgi vermişken ${ }^{2}$ bu eserde yazar transkripsiyon sistemi hakkında bilgi vermemiştir. Yazarın kullanmış olduğu transkripsiyon sistemi şu şeklidedir:

a (।): /a/ araba - b (ب): /b/ balik (balık), kitab - c (ج): /dsch/ ekmekdschi (ekmekçi) - ç (๕): /tsch/ ütsch (üç), tschingiane (çingene) - d (b,د): /d/ dört, dokuz - e (l): /e/ ewwel (evvel) - f (ف): /f/ fark - h (৯): /h/ hazir (hazır) - h (ح): /h/ ahwal (ahval) - h ( $(\dot{\mathcal{C}): ~ / c h / ~ c h a b e r ~(h a b e r), ~ / h / ~ b a h t s c h e ~(b a h c ̧ e) ~-~} \mathbf{1}$ (ى): /i/ alti (altı), güzel kiz (güzel kız); /y/ kyzkanmak (kıskanmak), kyz oglan (kız oğlan) - i ( (): /i/ iki; /y/ fölerfyn (söylersin), ne idy (ne idi) - k (ك) : /k/ kitab (kitap); /g/ göftermek, ruzgiar, /j/ güjerdschin (güvercin), bej (bey), mejer (meğer), ijiz (ikiz); /n/ bana; /ng/ janglifch - ḳ (ق): /k/ kumasch (kumaş), /h/ tschahtschir (çakşir), ahtsche (akçe) - $\mathbf{l}$ (J): /l/ lekke - m (९): /m/ merhamet - n (ن): /n/ namkör, /m/ namkör - o (و): /o/ orman - ö (و): /ö/ örümdschek (örümcek), /o/ gonülden (gönülden) - p (ب):

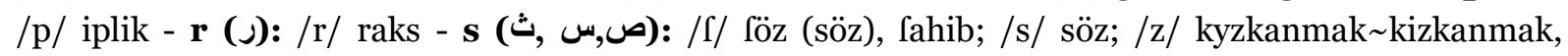
kizkandsch - ş (ش): /sch/ besch; /sh/ gümüsh - t (ط): / / / tabut, tasch (taş), /d/ dadfiz - u (و): /u/ bujun (bugün), bulut; /ü/ türündsch (turunç), /o/ kondak (kundak) - ü (و): /ü/ üfürmek, /ö/ bökmek (bükmek) - v (و): /w/ wiran (viran), /f/ fesfefe (vesvese) - y (s): /j/ jokusch (yokuş), /i/ kuiruk, /ø/

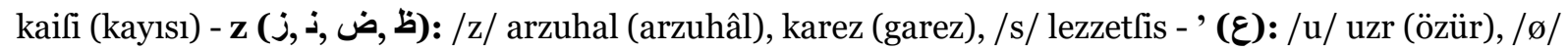
iitibar, maarifet - $\dot{\mathbf{g}}(\dot{\xi}):$ /g/ magrur, kigildschim (kıvılcım), /k / kairet, /gh/ ghalib olmak, /ø/ foutmak

\subsection{Eserin Bölümleri}

\subsection{1.Ön Söz}

Yazar, kitabın ön sözünde (ss. 3-4) Türkçe öğrenmek isteyen Almanların Meninski’nin eserindeki Arapça ve Farsça kuralların ve unsurların çokluğundan dolayı Türkçe öğrenmekte zorlandıklarını söyler. Türkçe öğrenmeyi kolaylaştırmak amacıyla daha sade bir kitap hazırlamayı amaçladığını, bunu yaparken de Almanların yazı ve telaffuzlarını dikkate aldığını belirtir. Kendi eserinin Meninski'nin

Gulıelmo Seaman (1670). Grammatica Linguae Turcìcae. Oxoniae; Megiser Hieronymus (1612). Institutionum linguae Turcicae, libri quatuor [...].Leipzig; Hindoglu, Artin (1834). Grammaire théorique et pratique de la langue turke. Paris; ... 
eserinden bu yönüyle ayrıldığını fakat konuşma metinlerini Meninski’nin eserinden alındığını ifade eder.

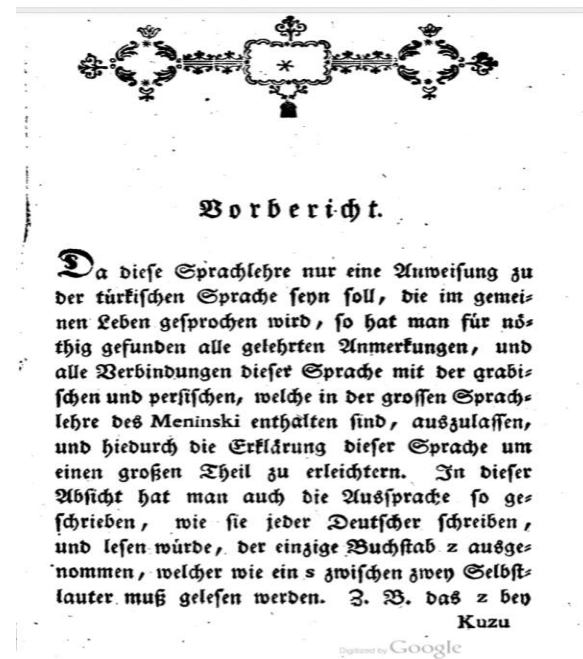

Resim 2. Eserin ön sözü

\subsubsection{Birinci Bölüm}

Birinci bölümde isim ve isim çekimleri dört alt başlık halinde işlenmiştir (ss. 5-13).

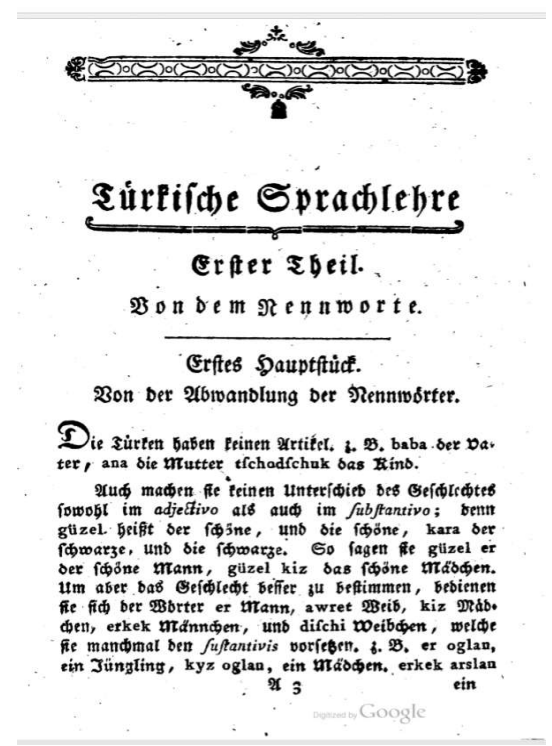

Resim 3. Birinci bölüm

Birinci bölümün birinci alt başlığında isim çekimleri ve çekimlerinde görülen değişmelere, Türkçe kelimelerde cinsiyetin olmadığına, cinsiyetin bazı durumlarda bazı kelimelerle belirtildiğine, isimlerde çokluk için $+L A r$ ekinin kullanıldığı hakkında bilgi verilmiştir (ss. 5-8). 

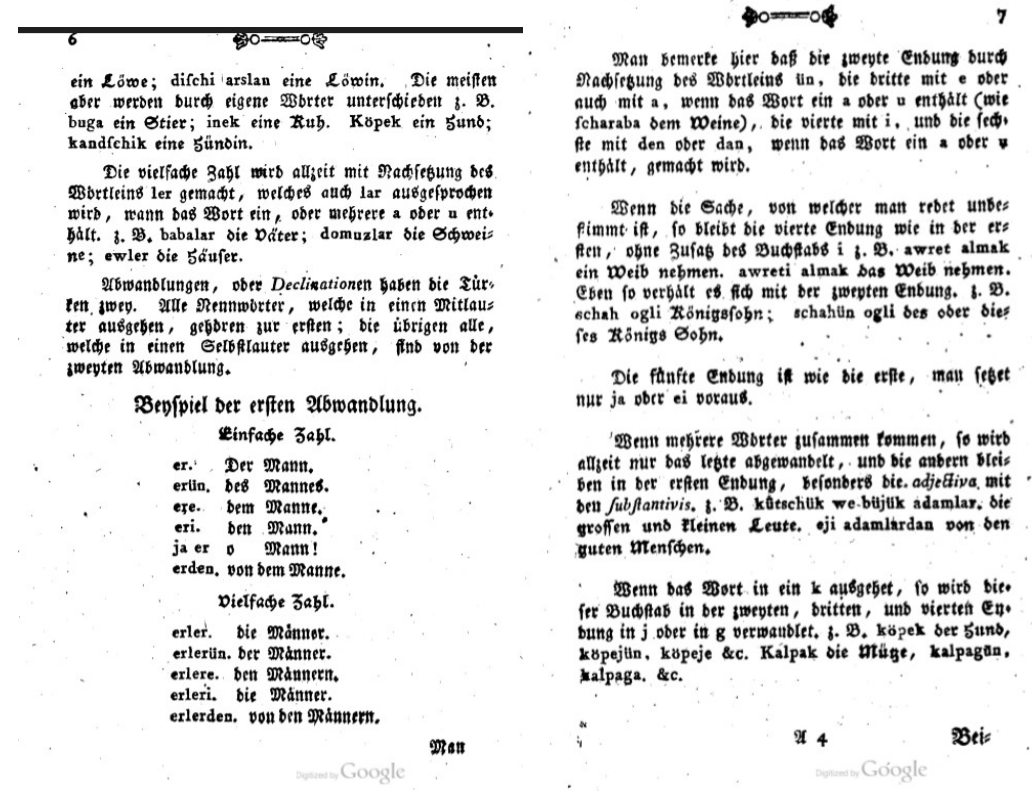

Resim 4. İsim çekimi

Bu bölümde dikkat çeken bazı özellikler:

1. İlgi hâli çekimi kalın ve ince ünlülü kelimelerden sonra +Un, +nUn'dür. Örn.: erün (des Mannes), erlerün (der Männer), schahün ogli (des oder diefes Königs Sohn), babanün (des Vaters), babalarün (der Väter)

2. Sert süreksiz ünsüzlerden k ile biten bir kelimeye ünlü ile başlayan hâl eklerinden biri getirilirse kalın ünlülü kelimelerde $\mathrm{k}>\mathrm{g}$, ince ünlülü kelimelerde $\mathrm{k}>\mathrm{j}$ (y)’ye dönüşür. Örn.: köpek (der hund) > köpejün, köpeje; kalpak (die Mütze) > kalpagün, kalpaga.

3. Ünsüzle biten kelimelerden sonra ilgi hâli eki + nün olmasına rağmen su kelimesi sunün yerine sujun şeklinde kullanılır.

Birinci bölümün ikinci alt başlı̆̆ında karşlaştırma, derecelendirme ve üstünlük belirten kelimelere değinilmiştir (ss. 8-9). Karşlaş̧tırma için Türkçede daha ve çok kelimelerinin, üstünlük için ise pek, gayet ve ziyade kelimelerinin kullanıldığı belirtilmiştir. 


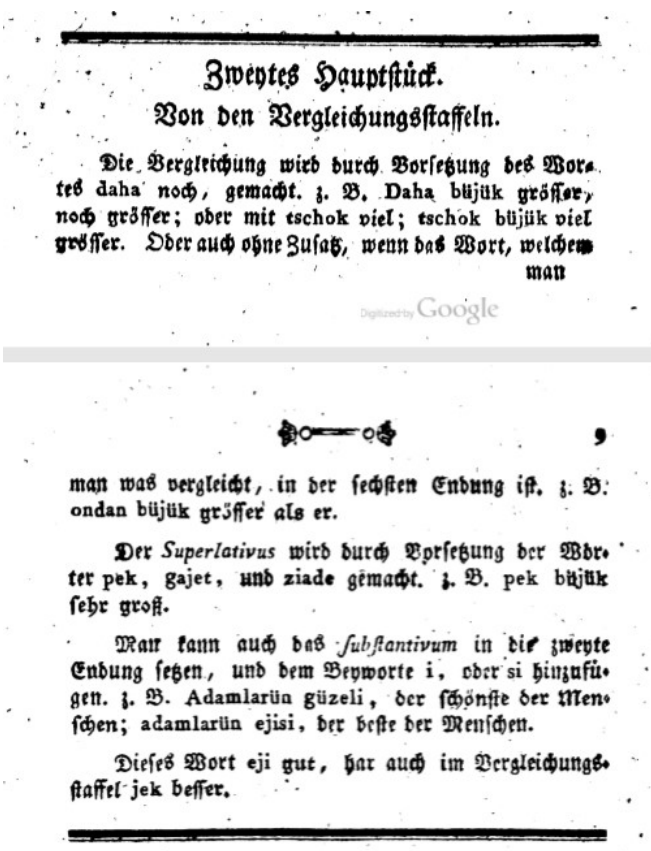

Resim 5. Karşlaştırma, derecelendirme ve üstünlük belirten kelimeler

Birinci bölümün üçüncü alt başlı̆̆ında isimden isim yapma eklerinden $+d s c h i(c i),+d s c h i k(c i k),+l i k$, $+l u ̈,+k i,+t s c h e$ (çe) ve fiilden isim yapma eklerinden -ma, -isch (iş), -üm ekleri ve bunların bazı işlevleri örneklerle gösterilmiştir. Pekiştirme yapmak için ise $m, p, r, s$, ünsüzlerinin kullanımına değinilmiştir (ss. 9-11).

\section{Drittes Sauptetiut.

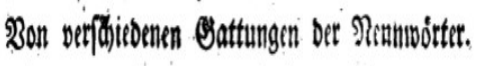

A. Bemin man eitteut Borte dschi nadiesert, fo ents Aebet bab nomen actoris baraut. Diefers dschi giebt

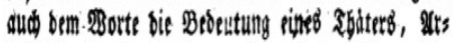

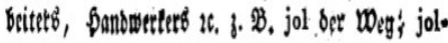
dschi ein Xeifender; tschoha das $\mathbb{E} u$ ud; t thhohadschi ein Tubogandler; exmek Broo; ekmekdschi ein 3 a $^{2}$.

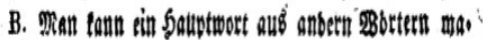
dent: .
I. PBent mant von ber unbefiummten Xatt (infritioo) bees seritwortes bas Enbewort mek ober mak aubs? It fist, unb bafiut isch feget. 6. B. gulaek lateen; gülisch Sas Laøen. Bakmak ífaum; bakisch A 5 in

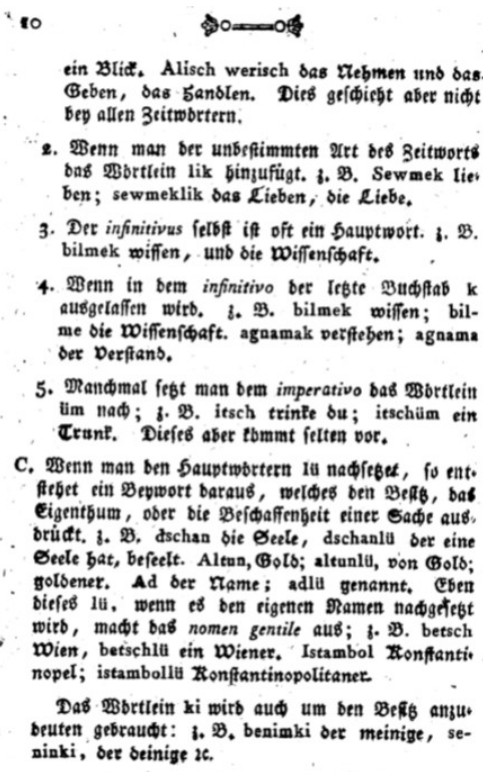

2. 2 Benn man ber unbeffimmten art beb Bettworts bas 2 Bbrttrin lik binfufügt. 3. B. Sewmek tiev ben; sewmeklik das Rieben, bie Riebe.

3. Der infinitivus felbf if oft ein 5auptwoit. $\mathfrak{3}, \mathfrak{B}$. bilmek wiffen, unb bie wiffenf́d,aft.

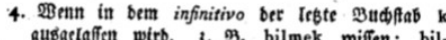
me bie roiffenfídaft. agaamak perfeben; agnams Der Derfans.

5. פRandmat fét man bem imperativo bas $r b b r t t e i n$ lim nad; ; 3 . 2. itsch trinte bu; itschüm ein đrant. Diefés aber tbmint felten vor.

C. 23 enn man ben 5auptwbettern tu nadireget, fo ent.

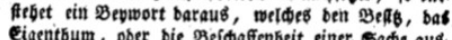
Eigentbum, ober bie Beifdaffengrit einer Sadec aus. bruatt. 3. 2 . dschan bie Eeele, dschanlu ber eine gotbener. Ad ber rame; adla genernte Gben biefes lu, went ef ben tigenen gamen na wirb, mađt bas nomen gentile aus; ;. PB. betsch woien, betschll ein wiener. Istambol Zronfantic nopel; istambollt Ř Ronfantinopolitaner.

Dab 2Bbrttein ki wirb aud um ben Beff anzu* beutent gebraudt: 3 . 2 , benimki ber meinige, seninki, bet beinige 26

Resim 6. Bazı eklerin kullanımları

Bu bölümde dikkat çeken bazı özellikler: 
1. dschi eki yuvarlak ve düz ünlülü kelimelerden sonra düz ünlülüdür. Örn.: jol (der Weg) > joldschi (ein Reifender), ekmek (Brod) > ekmekdschi (ein Bäck)

2. Sahiplik veya bir şeyin doğasını ifade etmeye yarayan ek +lü şeklindedir. Örn.: Altun (Gold) > altunlü (von Gold), betsch (Wien) > betschlü (ein Wiener), Istambol (Konftantinopel) > Istambollü (Konftantinopolitaner), iki dillü (zweyzüngig)

3. Küçültme eki dschik sert süreksiz ünsüzlerden k ile biten bir kelimeye getirilirse kelime sonundaki ünsüz düşer. Örn.: köpek (Hund) > köpedsckik (Hündlein)

4. Sifat veya zarflara getirilen tsche ve dschek ekleri sert süreksiz ünsüzlerden k ile biten bir kelimeye getirilirse kelime sonundaki ünsüz düşer. Örn.: kütschük (klein) > kütschütsche (etwas klein), kütschük (klein) > kütschüdschek (etwas klein), büjük > büjüdschek (etwas groß)

Birinci bölümün dördüncü alt başlığında Türkçedeki sayı sistemi işlenmiştir. Yazar sayı sisteminde Almancadan farklı olarak onlu ve yüzlü basamaklarda basamaklar arasına birleştirme işlevinde bir bağlacın girmediğine işaret etmiştir. Bunlara ilave olarak sayıların sıfat olarak kullanılma şekillerine, üleştirme sayılarına (yarım, çeyrek, buçuk), sıra sayısı belirtmek için sayılara +indsch (inci) eki getirildiğine, üleştirme sayılarının sayıya + scher (şer) eki getirilerek yapıldığına örnekler verilerek değinilmiştir (ss. 12-13).

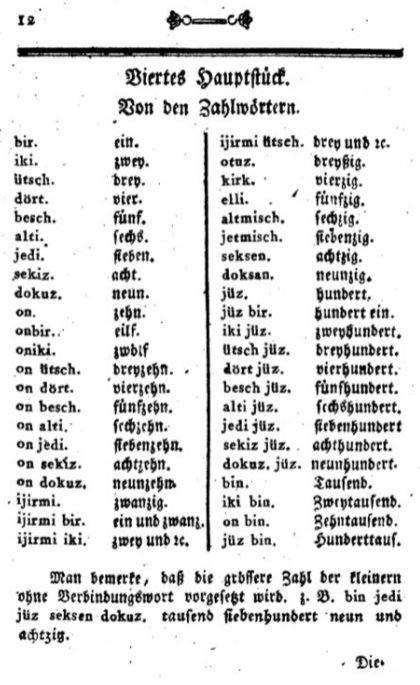

Resim 7. Saylar

1. Yazar iki (zwei) olarak vermiş fakat sözlük kısmında ikiz kelimesini ijiz (zwilling) şeklinde kullanmıştır.

\subsection{3. İkinci Bölüm}

İkinci bölümde zamirler konusu işlenmiştir. Yazar zamirleri üç alt başlıkta ele almıştır (ss. 14-19). 


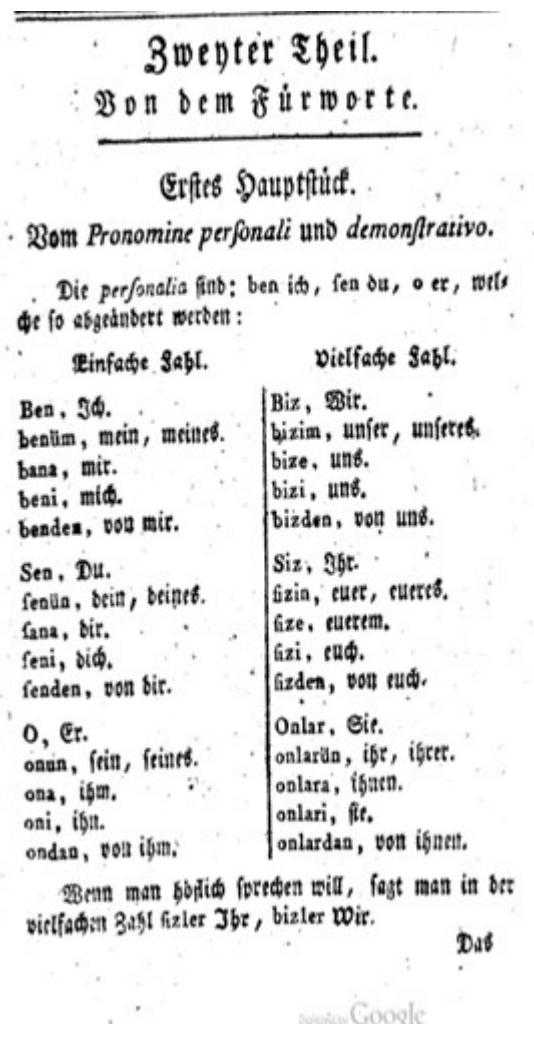

Resim 8. İkinci bölüm

İkinci bölümün birinci alt başlığında kişi ve işaret zamirleri; saygı amaçlı ve kibar konuşmalarda sizler ve bizler zamirlerinin tercih edilmesi gerektiği; işaret zamiri için bu, schu (şu), bunlar, schunlar (şunlar)'ın kullanıldığı; dönüşlülük zamirinin kendi olduğu üzerinde durulmuşstur (ss. 14-15).

Bu bölümde dikkat çeken bazı özellikler:

1. İlgi hâli eki ben ve sen zamirlerine yuvarlak ünlülü, siz zamirine düz ünlülü gelir. Çokluk birinci kişi zamiri biz iki türlü kullanıma sahiptir. Örn.: benüm (mein, meines), fenün (dein, deines), bizim bizüm (unfer, unferes), fizin (euer, eueres)

2. İlgi hâli eki, o kişi zamirine veya bu ve şu işaret zamirine gelirken kalınlık incelik uyumuna uyar. Zamir çokluk eki aldığında bu kural bozulmuştur: onun (fein, feines), onlarün (ihr, ihrer), bunun - fchunun (diefes), bunlarün - fchunlarün (diefer)

3. kendi dönüşlülük zamirinin hâl çekimi şu şekildedir: kendinin, kendije, kendiji, kendiden. Örnek kullanım: kendije zarar etti (er hat fich felb ften gefchadet), kendi kendiden (von fich felbft, für fich)

İkinci bölümün ikinci alt başlığında $k i$ bağlacına ve sıfat yapan $k i$ ile sıfat fiil -dug (duk) ekine; soru zamiri ve sıfatı kim, kime, ne, neden, nasil, ne türlü, ne kadar, hangi, nerelü’nün kullanımına; belgisiz zamir bir kimse, kimse, hitsch (hiç) bir kimse, bir şey, her, herkes'in kullanımına yer verilmiştir (ss 1517).

İkinci bölümün üçüncü alt başlığında iyelik ekleri verilmiştir. Kelime ünlü ile biterse iyelik eklerinin $+m$, $+n,+s i,+m \ddot{z},+n u ̈ z,+l e r i$; ünsüz ile biterse $+\ddot{u} m,+$ ün veya $+i n,+i$ veya $+\ddot{u},+\ddot{u} m u ̈ z,+\ddot{u} n \ddot{z},+$ leri şeklinde kullanıldığı; benim, senin kişi zamiri ile yapılan tamlamalarda tamlanan ekinin (birinci kişi iyelik eki) kullanılmasının zorunlu olduğu "benim baba yerine benim babam" fakat benim ve senin 
zamirlerinin kullanımının zorunlu olmadı̆̆ı; üçüncü kişilerde ise iyelik zamiri $i$ ve si eklerinin kullanıldı ̆̆ına değinilmiştir (ewin sahibi). Yazar bu açıklamaların ardından tamlamanın belirli olması durumunda ewin sahibi şeklinde kullanıldığına, belirsiz olması durumunda ise ew sahibi denildiğine yer verir. (ss. 17-19).

Bu bölümde dikkat çeken bazı özellikler:

1. İyelik ekleri isimlere eklenirken ünlü uyumu konusunda bir standart yoktur.Teklik 1. ve 2. kişi iyelik eklerinde ünlü uyumu görülürken çokluk 1. ve 2. iyelik eki +(ü)müz ve +(ü)nüz şeklindedir. Örn.: ewi (fein Haus), kürkü (fein Pelz); babamüz (unfer Vater), babanüz (euer Vater), ewümüz (unfer Haus) ewünüz (euer Haus).

\subsection{4. Üçüncü Bölüm}

Bu bölümde filler konusu işlenmiştir. Fiiller üç alt başlıkta ele alınmıştır (ss. 20-37).

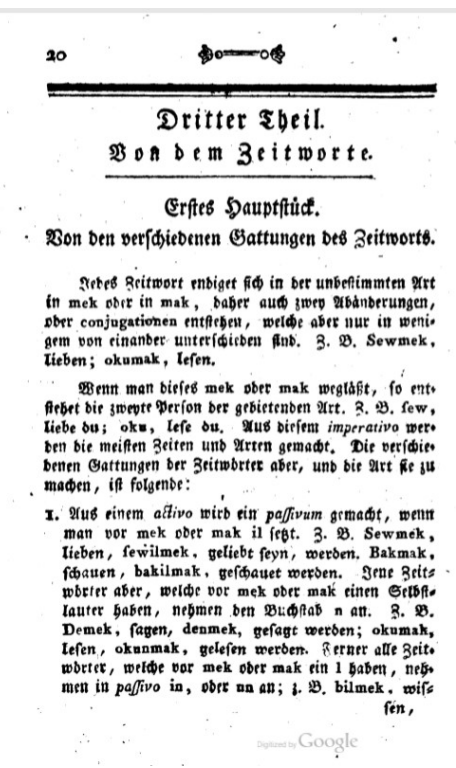

Resim 9. Üçüncü bölüm

Üçüncü bölümün birinci alt başlığında fiilden isim yapım ekleri mek ve mak; edilgen eki -il, $-n$; ettirgenlik eki dür, - $t$ ve - $d$, -ür; dönüşlülük eki - $n$; işteşlik eki -sch (ş), -isch (iş); olumsuzluk eki -me ve - $m a$, yeterliliğin olumsuzunun eme ve $a m a$, isimden fiil yapım eki la ve le, şimdiki zaman eki -jor (yor) ve fillerle kullanılan yardımcı filler etmek, eylemek, japmak (yapmak), kulmak hakkında bilgi verilmiştir (ss. 20-23).

Üçüncü bölümün ikinci alt başlığında $i$ ek fiili ve idim, imischim (imişim), imischidim (imişdim) şekilleri; ol- fiili ve oldum, olmisch (olmiş) idim, olurum, olacagim, ol, olaidim, olurdum, olmüsch (olmüş) olam, olmusch (olmuş) olaidim, olam, olsam, olmisch (olmiş) isem şekillerine ve bunların çekimlerine örnekler verilmiştir. Devamında iken, olurken, olup, olundscha (olunca), olan idük ve olduk, olmalü, olaldan kelimelerinin anlam ve kullanımları üzerinde durulmuştur. İkinci alt başlığın sonunda ise kısaca dejil, war, jok (yok) olumsuzluk bildiren kelimeler verilmiştir (ss. 23-28). 
Üçüncü bölümün üçüncü alt başlı̆ğında fiillerde basit ve birleşik zaman çekimleri; fiillere gelen -indsche (ince) 'sewindsche', -megin 'sewmegin', -er iken 'sewer iken', -üp 'sewüp', idschek (icek), -erek, -er, -en, -idschi (ici), -dük, -meden ve -madan, -eli eklerinin bazı işlevleri hakkında bilgi verilmiştir (ss. 29-37).

Bu bölümde dikkat çeken bazı husular:

1. İstek çekiminde çokluk 1. şahıs eki -uz ve -jüz şeklindedir. Örn.: olauz (daß wir feyen), fewejüz (daß wir lieben).

2. İstek çekiminde çokluk 2. şahıs eki - fiz ve - finiz şeklindedir. Örn.: olafiz (daß ihr feyen), fewefiniz (daß ihr lieben)

3. İsimlerde olumsuzluk dejil ve deil olarak kullanılır: ewim büjük dejil (mein Haus ift nicht groß), Korkma, türktfche föjlemek o kadar gütfch deil.

\subsubsection{Dördüncü Bölüm}

Dördüncü bölümde bazı gramer kurallarına yer verilmiş olsa da daha çok konuşma cümleleri ve sözlük bölümü bulunmaktadır (ss. 38-41).

Dördüncü bölümün birinci alt bölümünde sıfatın zarf olarak kullanımı, ile edatı, millet isimlerinden dil ismi yapan $+t s c h e(c ̧ e)$ eki, soru ve işaret zamirlerine $+e,+d e,+d e n$ hal eklerinin getirilmesi ve soru edatı $m i$ işlenmiştir (ss. 38-39).

Dördüncü bölümün ikinci alt bölümünde bulunma hâl eki, ayrılma hâl eki, olumsuzluk bildiren siz eki ve üzre, dek veya degin, göre, dogru, karschi (karşi), jakin (yakin), ütrü, sonra, ewwel, kairi ve made, ile, itschin (için), kibi (gibi) hakkında bilgiler bulunmaktadır (ss. 39-41).
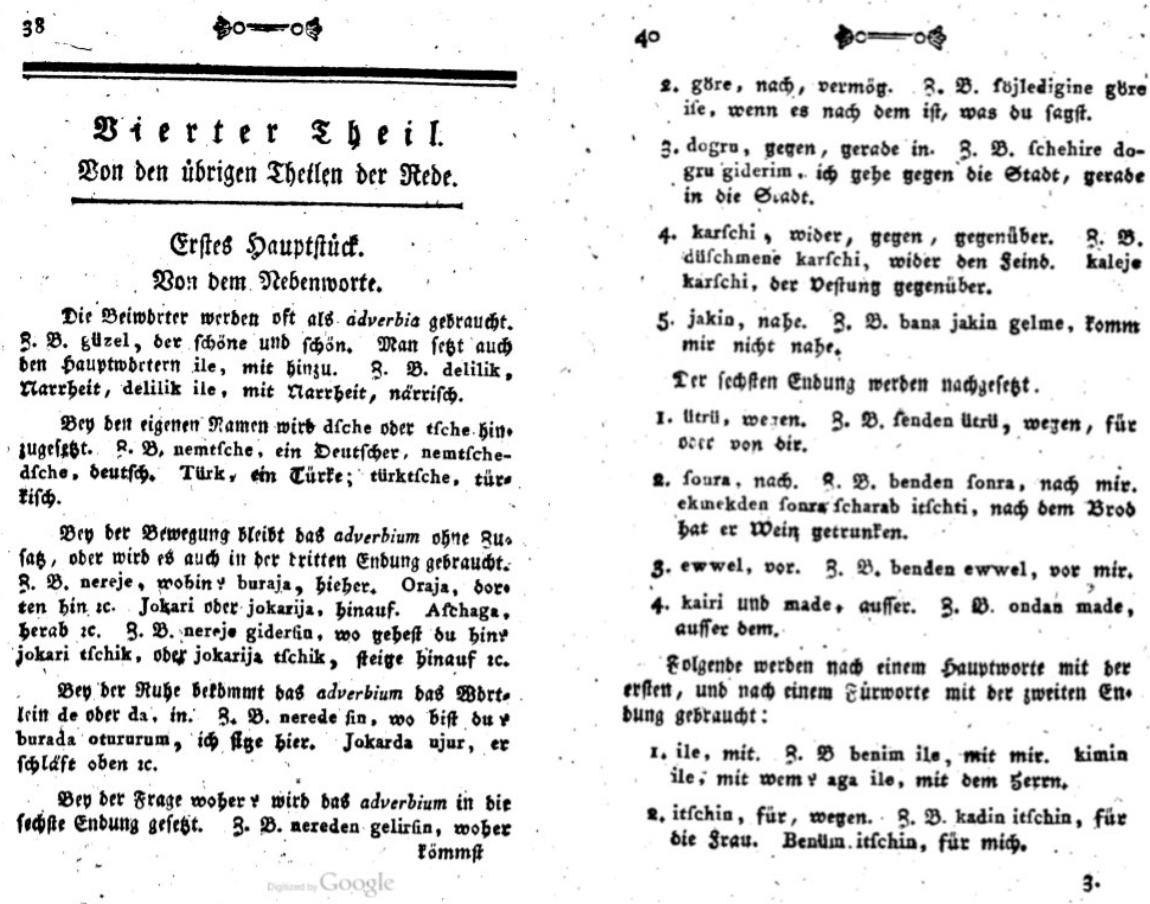

Resim 10. Bazı zarflar ve edatlar 
Dördüncü bölümün üçüncü alt bölümünde on başlıkta konuşma cümleleri ve bunların Almanca karşılıkları bulunmaktadır: 1.sabah vaktinde ziyaret (ss. 42-44), 2.Türkçe konuşmak (ss. 44-46), 3.yazmak (s. 47-48), 4. dost ile sohbet (ss. 48-51), 5. hava durumu (ss. 51-52), 6. seyir (ss. 52-56), 7. haber (ss. 56-57), 8. iki dost arasında (ss. 58-60), 9. bir kimseden sual etmek (ss. 60-62), 10. bir şey satın almak (62-64).

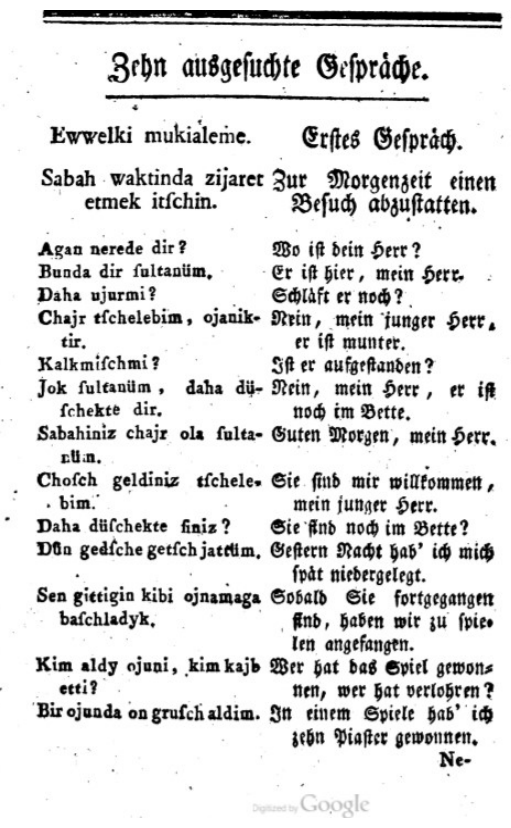

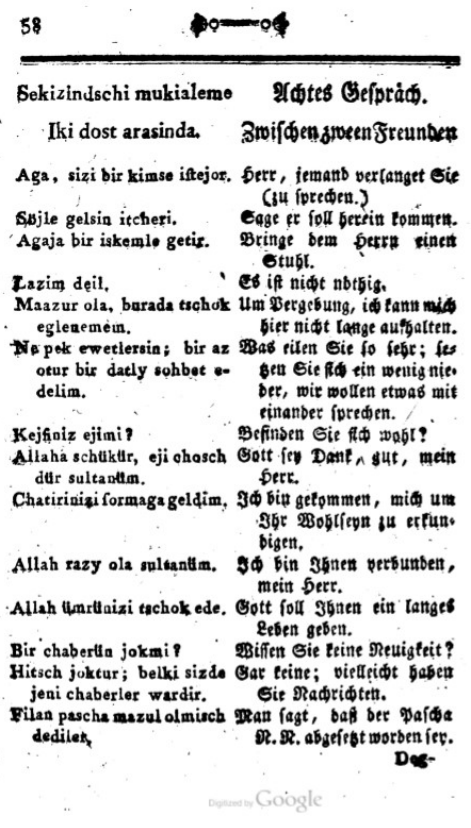

Resim 11. Konuşma cümleleri

Karşılıklı konuşma cümlelerinin devamında günlük hayatta çokça kullanılabilecek buraja (buraya) gel, dün ne?, kahwaltimi getir, bu elma tschürük (çürük) dir, gezmege gidelim, pendschereleri atsch (pencereleri aç) gibi değişik konularda 250'ye yakın cümle kalıpları bulunmaktadır (ss. 65-76). 

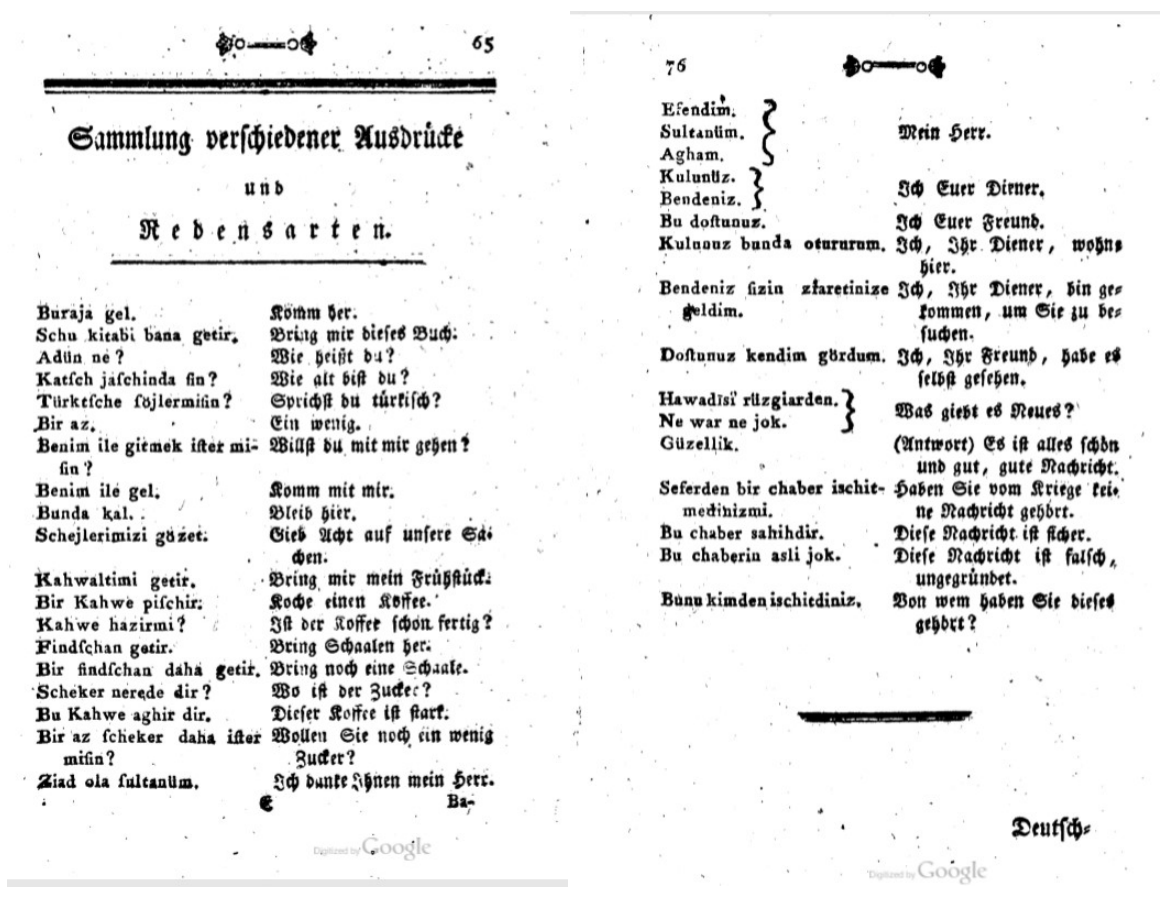

Resim 12. Değişik kalıptaki cümleler

Bu bölümde dikkat çeken bazı özellikler:

1. Yazar yedinci mükâlemede kağıt sözcügünü gazete anlamında kullanmıştır: kiahadlar ne derler? (Was fagen die Zeitungen?)

Dördüncü bölümün son bölümünde yazar önemli gördüğü kelimelerden oluşan 101 sayfa AlmancaTürkçe sözlük hazırlamıştır (ss. 77-178).
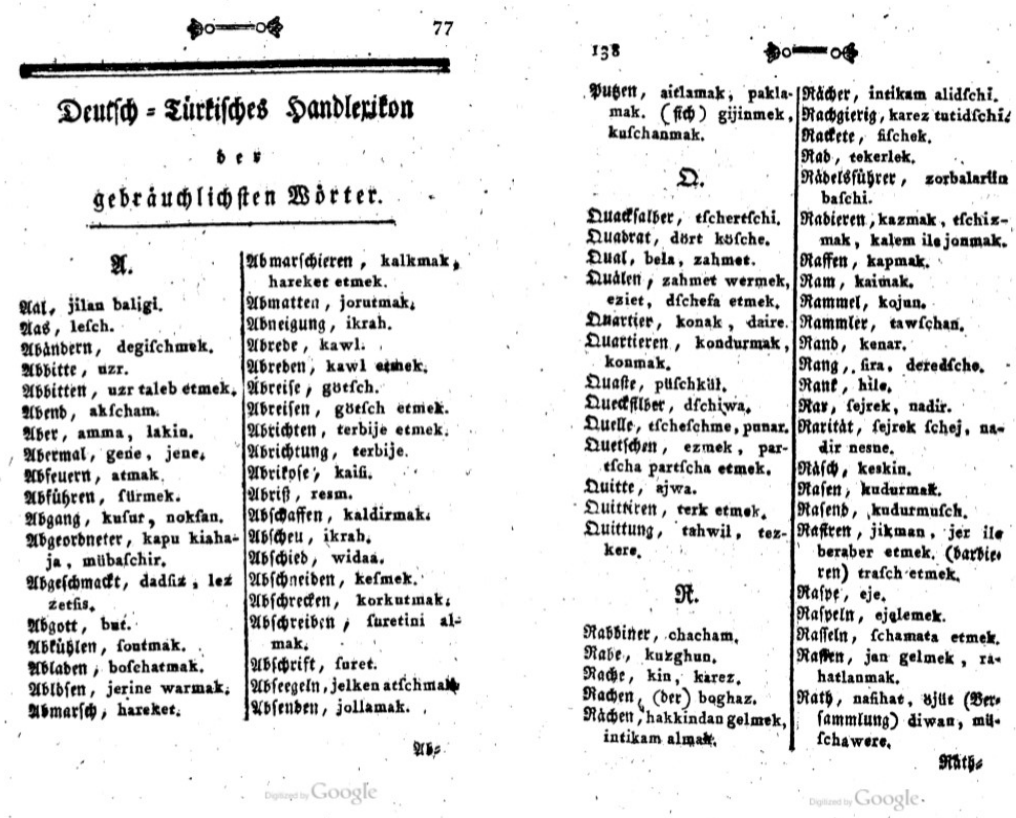

Resim 13. Sözlük 
Bu bölümde dikkat çeken bazı özellikler:

1. Bazı kelimelerde ünsüz ikizleşmesi görülür. Örn.: lekkelemek (lekelemek) "beflecken”, iffirmak (ısırmak) "beiffen”, kaffap tükiani (kasap dükkanı) "fleifchbank”, battürmak (batırmak) "eintunken"

2. Bazı kelimelerde sızıcılaşma görülür. Örn.: ahtsche (akçe) "geld"

3. Bazı kelimelerde ünlü türemesi görülür. Örn.: uruba (urba) "kleid”, bikir (bikr) "jungfrau”

4. Bazı kelimelerde süreksizleşme görülür. Örn.: tschahtschir (çakşir) "hofen"

5. Bazı kelimelerde akıcılaşma görülür. Örn.: düjün (düğün) "beilager"

6. Bazı kelimelerde akıcı ünsüzler arası değişmeler görülür. Örn.: namkör (nankör) "undankbar"

7. Bazı kelimelerde ince ünlünün kalın ünlüye dönüştüğü görülür. Örn.: gonülden (gönülden) "inftändig"

8. Bazı kelimelerde dar ünlünün geniş ünlüye dönüştüğü görülür. Örn.: ojandirmak (uyandırmak) "erwecken"

9. ع ( ( ) sesinin erimesi neticesinde uzun ünlü oluştuğu görülür. Örn.: iitibar (اعتبار) "achtung”, maarifet (معرفت) "gelehrfamkeit"

10. Bazı kelimelerde ünsüz türemesi görülür. Örn.: fchajir ( شاعر) “dichter”

11. Türk sözcügü, hem bir ırk adı olarak hem de İslam dinini kabul edenlerin adı olarak kullanılmıştır. Türk: türk, müsülman.

12. Asma için dikik karşılığ 1 verilmiştir. Rebe, reben: dikik.

\section{Sonuç}

3.1. Eserin isimsiz olması ve eser hakkında çoğu kaynakta bilgi bulunmamasına rağmen 'Die K.K. Orientalische Akademie zu Wien, ihre Gründung, Fordbildung und gegenwärtige Einrichtung' adlı eserde Thomas Chabert adı altında bu eserin verilmiş olması eserin yazarının Thomas Chabert olduğunu gösterir.

3.2. Thomas Chabert 1789 tarihli "Kurze Anleitung zur Erlernung der türkischen Sprache, für Militär Personen. Sammt einer Sammlung von nützlichen Gesprächen, Ausdrücken und Redensarten und einem Handlexikon der gebräuchlichsten Wörter" adlı eserinin askeri personel için hazırlanmış bir eser olduğunu belirtse de içerik olarak yapmış olduğumuz incelemede askeri personele has olabilecek bir bölüm tespit edilememiştir. Eserde kısaca Türkçenin gramer kuralları, günlük hayatta herkes için gerekli olabilecek cümle kalıpları ve Meninski’den alınmış konuşma cümleleri verilmiştir. Eserin sonunda da Almanca-Türkçe sözlük bulunmaktadır.

3.3. Yazarın yıllarca Doğu dilleri pröfesörlüğü yapmış olması ve 1810 yllında Hikâyet-i İbda-i Yeniçeriyân bâ Bereket-i Pîr-i Bektaşiyân Şeyh Hacı Bektaş Velî-i Müslimân adlı tiyatro eserini yazacak kadar Türkçeye hâkim olması bu eserin önemini yabancılara Türkçe öğretimi açısından daha da artırmaktadır. Eserin ön sözünde de belirtildiği üzere yazarın kısa ve kolay bir Türkçe öğretim kitabı hazırlamayı amaçlamıştır. Bu nedenle eserinde fazla detaya girmeden en önemli gramer kurallarına ve en çok dikkat edilmesi gereken hususlara yer vermiştir. Eserin bu özelliği yabancılara Türkçe öğretimi noktasında Türk araştırmacılara fayda sağlayacaktır.

3.4. Bu eser daha sonraki yıllarda yazılmış olan bazı eserlere kaynaklık etmiştir. Bu sebeple döneminde ve sonraki dönemlerde Türkçe öğretimi için önemli bir kaynak olduğu söylenebilir. Yazarı belli olmayan 1828 tarihli "Kurzgefafzte türkisch=deutsche Sprachlehre- Mit einer Sammlung der gebräuchlichften Wörter, kleiner Conftructionen und Redensarten - Nebst zwölf Gesprächen und zehn Gefchichten in türkischer deutscher und französischer Sprache" adlı çalışma bir çeşit Thomas Chabert’in çalışmasının 
kopyası şeklindedir. İki çalışma arasındaki fark birinin Türkçe ve Almanca olarak hazırlanmışken diğerinin Türkçe, Almanca ve Fransızca olarak hazırlanmış olmasıdır3.

Aşağıda her iki eserde bulunan konuşma cümlelerinden verilen örnekler birebir aynıdır. Yalnız 1828 tarihli eser Türkçe, Almanca ve Fransızca olarak hazırlanmıştır.

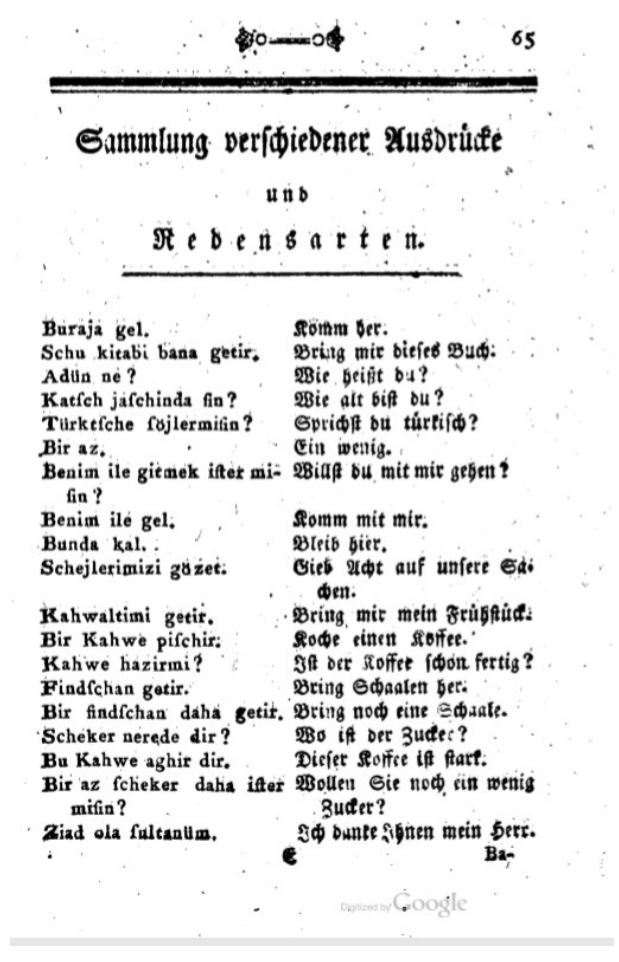

1789 tarihli eser

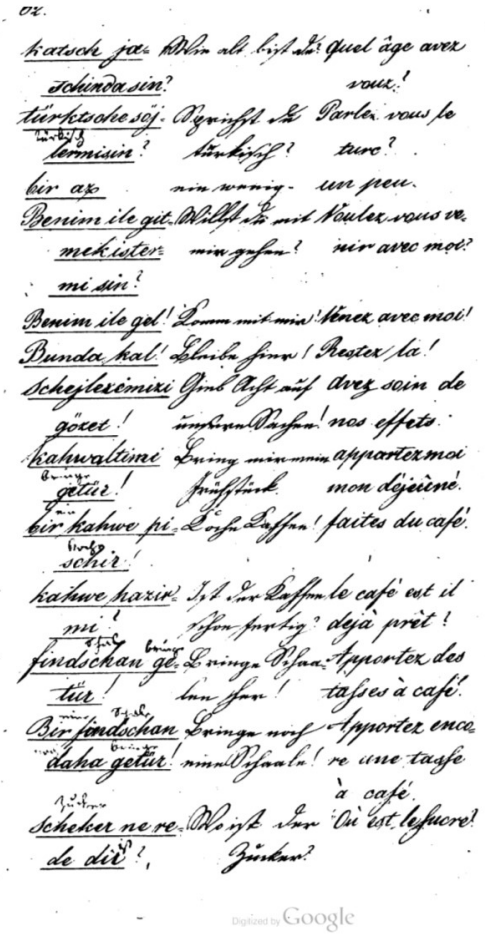

1828 tarihli eser

Resim 14. İki eserdeki kalıp cümleler sayfası

3.5. Sözlük kısmında verilmiş bazı kelimelerin yazımlarının konuşma özelliklerine göre verildiği görülmektedir4.

3.5.1. Anadolu ağızlarında ünsüz ikizleşmesi yaygın olarak görülen bir ses olayıdır: Yazarın lekelemek (لكهلكك) > lekkelemek şeklinde vermiş olması ağız özelliğini yansıtan bir husustur.

3.5.2. Anadolu ağızlarında görülen diğer bir ses olayı da Arapça kelimelerdeki (ع) ayın sesinin erimesiyle yanındaki ünlünün uzun telaffuz edilmesidir. Eserin sözlük kısmında Arapça kökenli olan ítibār ( اعنبار) > iitibar şeklinde verilmesi yine ağız özelliğini yansıtan bir husustur.

\section{Kaynakça}

Argunşah, M.- Güner, G. (2015). Codex Cumanicus. İstanbul: Kesit Yayınları.

Bartholomæo G. (1567). De Tvrcarvm Moribvs Epitome. Ioan Tornaesivm: Lvgdvni Apvd.

1828 tarihli eser için bakınız: Bekar, B. (2017). 1828 Yılında Yazılış Türkçe, Almanca ve Fransızca Bir Transkripsiyon Metni. Route Educational and Social Science Journal. Volume 4/7, December 2017.

${ }^{4}$ Leyla Karahan (2017). Anadolu Ağızlarının Sınıflandırılması. Ankara: TDK; Tuncer Gülensoy (1988). Kütahya ve Yöresi Ağızları. Ankara: TDK. Zeynep Korkmaz (1956). Güney-Batı Anadolu Ağızları Ses Bilgisi, Ankara: TDK. 
Bekar, B. (2017). 1828 Yılında Yazılmış Türkçe, Almanca ve Fransızca Bir Transkripsiyon Metni. Route Educational and Social Science Journal, Volume 4/7, December 2017.

Chabert, T. (1789). Kurze Anleitung zur Erlernung der türkischen Sprache, für Militär Personen. Sammt einer Sammlung von nützlichen Gesprächen, Ausdrücken und Redensarten und einem Handlexikon der gebräuchlichsten Wörter. Wien: Bei Löschenkohl, Kunsthändler am Kohlmarkt.

Die K. K. Orientalische Akademie Zu Wien, İhre Gründung, Fordbildung und Gegenwärtige Einrichtung (1839). Wien: Carl Gerold.

Dilaçar, A. (1986). Dil, Diller ve Dilcilik. Ankara: TDK.

Gökalp-Alpaslan, G.G. (2007). İlk Türkçe Oyunlardan Vakayi-i Acibe ve Havadis-i Garibe-i Keşfger Ahmed Üzerine Bir İnceleme. bilig Bahar 2007, sayı 41, ss. 41-68.

Gülensoy T. (1988). Kütahya ve Yöresi Ağızları. Ankara: TDK

Harsany, J. N. (1672). Colloquia Familiaria Turcico Latina Seu Status Turcicus Loquens. Coloniae Brandeburgicae.

Hazai, G. (2012). Türkiye Türkçesinin Dünü ve Bugünü. Ankara: TDK.

İmer K., Kocaman A. ve Özsoy A. S. (2011). Dilbilim Sözlüğü. İstanbul: Boğaziçi Üniversitesi Yayınları.

Jahrbücher Der Literatur. Vier und Funfzigster Band (1831). Wien: Carl Gerold.

Kartallığlu, Y. (2010). Bernardo da Parigi’nin Söz Kitabı 4oo Yillık İtalyanca-Türkçe Sözlük. Ankara: Gazi Kitabevi.

Korkmaz, Z. (1956). Güney-Batı Anadolu Ağızlarn Ses Bilgisi. Ankara: TDK.

Osmanische Sprichwörter (1865). Die K.K. Orientalische Akademie in Wien.

Vardar, B. (1980). Dilbilim ve Dilbilgisi Terimleri Sözlüğü. Ankara: TDK Yayınları.

Yağmur Ö. (2014). Erken Dönem Türkçe Transkripsiyon Metinleri ve Bunların Dil Araştırmaları Açısından Önemi. FSM İlmî Araştırmalar İnsan ve Toplum Bilimleri Dergisi, 4 (2014) Güz, ss. 201-217.

Yllmaz, Y. - Demirci, O. (2016). Preindl’in Grammaire Turque’ünde Türk Atasözleri. Turkish Studies, 11(20), 25-40.

Yllmaz, Y. - Özveren, M. S. (2017). P.A. Jaubert'in Elements De La Grammaire Turque'ündeki Atasözleri. RumeliDE Dil ve Edebiyat Araştormaları Dergisi. Sayı 9. 31-68.

Zenker, J. T. (1866). Türkisch, arabisch, persisches Handwörterbuch. Leipzig: Engelmann Verlag 